\title{
CAMA DE AVES ASSOCIADA A ADUBAÇÃO NITROGENADA NO CULTIVO DO MILHO
}

Pedro Mesquita de Lima Neto ${ }^{1}$, Darly Geraldo Sena Júniorr ${ }^{2}$, Danyllo Santos Dias ${ }^{3}$, Simério Carlos Silva Cruz $^{2}$, Héliton de Oliveira Resende ${ }^{1}$, Marcelo Marques Costa ${ }^{2}$

${ }^{1}$ Universidade Federal de Goiás - UFG, Mestrando do curso de Agronomia, Campus Jataí, Go. ${ }^{2}$ Universidade Federal de Goiás - UFG, Docente do curso de Agronomia da, Campus Jataí, GO. ${ }^{3}$ Universidade de São Paulo - USP, Escola Superior de Agricultura "Luiz de Queiroz"- ESALQ, Mestrando em Agronomia, SP. E-mail: simerio cruz@yahoo.com.br

\section{RESUMO}

A utilização de resíduos animais provenientes da avicultura como fertilizante orgânico é uma maneira sustentável de utilização dos resíduos desse sistema de produção, porém ainda há a necessidade de mais estudos sobre a dinâmica de disponibilização dos nutrientes. $O$ objetivo deste trabalho foi avaliar o uso de cama de aves associada à fertilização nitrogenada na cultura do milho (Zea mays) e a disponibilização de nitrogênio da cama de aves durante três anos de cultivo. Foi utilizado o delineamento em blocos casualizados, em esquema fatorial $3 \times 5+1$. Os fatores consistiram de doses de cama de aves $(2,5$ e $8 \mathrm{Mg}$ ha $\left.{ }^{1}\right)$ e doses de nitrogênio $\left(0,50,100,150,200 \mathrm{~kg} \mathrm{ha}^{-1}\right)$. A testemunha recebeu fertilizante mineral na semeadura na dose de 120,80 e $20 \mathrm{~kg} \mathrm{ha}^{-1}$ de $\mathrm{P}_{2} \mathrm{O}_{5}, \mathrm{~K}_{2} \mathrm{O}$ e $\mathrm{N}$, respectivamente e em cobertura com $200 \mathrm{~kg}$ $\mathrm{ha}^{-1}$ de N. Foram feitas leituras do índice SPAD, altura de plantas, altura de espigas, produtividade, massa de cem grãos e número de grãos por espiga. As maiores doses de cama de aves utilizadas ( 5 e $8 \mathrm{Mg} \mathrm{ha}{ }^{-1}$ ) em três anos sucessivos, mesmo sem $\mathrm{N}$ em cobertura, propicia produtividade semelhante à testemunha com fertilizante mineral na cultura do milho, sendo assim, a cama de aves é alternativa viável na adubação da cultura do milho a longo prazo.

Palavras-chave: adubação orgânica; nitrogênio; Zea mays.

\section{POULTRY LITTER ASSOCIATED WITH NITROGEN FERTILIZATION IN THE CULTIVATION OF CORN}

\section{ABSTRACT]}

The use of animal residues from poultry as an organic fertilizer is a sustainable way to dispose of the production system, but there is still a need for further studies on the dynamics of nutrient availability. The objective of this work was to evaluate the use of poultry litter associated with nitrogen fertilizer in the corn (Zea mays) crop and the availability of nitrogen from the residue during three years of cultivation. The factors consisted of poultry litter doses $\left(2,5\right.$ and $\left.8 \mathrm{Mg} \mathrm{ha}^{-1}\right)$ and nitrogen doses $\left(0,50,100,150,200 \mathrm{~kg} \mathrm{ha}^{-}\right.$ $\left.{ }^{1}\right)$. The control group received mineral fertilizer at the dose of 120,80 and $20 \mathrm{~kg} \mathrm{ha}^{-1}$ of $\mathrm{P}_{2} \mathrm{O}_{5}, \mathrm{~K}_{2} \mathrm{O}$ and $\mathrm{N}$, respectively, and covered with $200 \mathrm{~kg} \mathrm{ha}^{-1}$ of $\mathrm{N}$. SPAD index readings, plant height, ear height, yield, one hundred grain mass and number of grains per spike were made. The highest doses of poultry litter ( 5 and 8 $\mathrm{Mg} \mathrm{ha}^{-1}$ ) in three consecutive years, even without $\mathrm{N}$ broadcast, propitiates similar yield to the mineral fertilizer control in the corn crop, thus, the poultry litter is an alternative viable in long-term corn crop fertilization.

Keywords: organic fertilization; nitrogen; Zea mays.

\section{INTRODUÇÃO}

O crescimento da agricultura na região Centro-Oeste atraiu muitas indústrias do setor avícola que se estabeleceram na região em busca de insumos para a produção de aves, gerando um grande acúmulo de resíduos desse sistema de produção.
Entre as opções para o uso dos resíduos de animais provenientes da avicultura, a aplicação como técnica de manejo de fertilizante orgânico pode ser uma boa opção, em termos agronômicos, econômicos, ambientais e sociais, desde que respeitados os critérios técnicos para sua aplicação (SARTAJ et al., 1997; KIEHI, 2010; 
ORRICO JÚNIOR et al., 2010).

A cama de aves é constituída de material excretado pelas aves, penas, ração desperdiçada e material absorvente usado no piso dos aviários e apresenta razoáveis teores de nutrientes devido à alta concentração destes nutrientes na dieta das aves (COSTA et al., 2009). Kiehl (2010) cita que as camas de aves possuem em média 2,5\% de Nitrogênio, 1,6\% de Fósforo, $2 \%$ de Potássio, 2,2\% de Cálcio, 0,5\% de Magnésio, 270 ppm de Zinco e 300 ppm de Mn. Trabalhos mostram efeitos benéficos da utilização de resíduos animais na adubação de culturas, como o aumento na produtividade da cultura do milho (BAYER, et al., 1999; PAVINATO et al., 2008; NOVAKOWISKI et al., 2013), além do aumento dos teores de matéria orgânica no solo.

Em função do teor de nitrogênio presente na cama de aves, Santos et al. (2014) consideram que este resíduo quando bem manejado, pode substituir parcial ou totalmente o fertilizante químico nitrogenado. Além disso, aumenta a capacidade de retenção de água, reduz a erosão, melhora a aeração e cria um ambiente mais adequado para o desenvolvimento da microbiota do solo pelo acréscimo de matéria orgânica (NAKAGAWA, 1992; SANTOS et al., 2004; KIEHL, 2010. A utilização adequada de dejetos parece ser viável para a minimização do uso de adubos químicos e consequentemente do custo de produção, uma vez que os valores dos resíduos orgânicos são normalmente baixos (SILVA et al., 2012).

Alguns fatores devem ser levados em consideração no momento da utilização da adubação com cama de aves, dentre eles a extração de nutrientes pela cultura, a taxa de mineralização dos elementos contidos na cama, o período de maior exigência de cada nutriente pela cultura, bem como as características físicas e químicas do solo (FELINI; BONO, 2011).
O fornecimento de nitrogênio no momento correto e em dose adequada, é fundamental para o ótimo desenvolvimento e crescimento da cultura do milho sendo o nutriente que mais onera seu custo de produção (BASTOS et al., 2008; NASCIMENTO et al., 2012), principalmente em função do valor elevado do fertilizante e das quantidades requeridas pela cultura. A definição da dose ideal de nitrogênio é difícil, devido à dinâmica do elemento no solo, que envolve volatilização, imobilização por microorganismos e lixiviação, além da diversidade de resposta dos híbridos de milho ao nitrogênio (GODOY et al., 2003).

Diante do exposto, e baseado no potencial da cama de aves como fonte orgânica de nutrientes, objetivou-se com este trabalho avaliar a utilização de cama de aves associada à fertilizante químico nitrogenado no desenvolvimento e na produtividade da cultura do milho (Zea mays) durante três anos de cultivo.

\section{MATERIAL E MÉTODOS}

O trabalho foi conduzido na Regional Jataí da Universidade Federal de Goiás durante três safras (2011/12, 2012/13 e 2013/14). O município de Jataí está localizado na micro-região do Sudoeste Goiano, com coordenadas 17053' S e 52ㄴㄱ' W e altitude de $680 \mathrm{~m}$, com temperatura e precipitação média anual de 22 ㅇ e $1.800 \mathrm{~mm}$, respectivamente.

O solo da área experimental foi classificado como Latossolo Vermelho distroférrico (EMBRAPA, 1999), com teores de 48,42 e $10 \%$ de areia, argila e silte, respectivamente. $O$ solo foi amostrado na camada de $0-20 \mathrm{~cm}$ e submetido a análise química, com resultados apresentados na Tabela 1.

Tabela 1. Análise química da área experimental antes da instalação do experimento.

\begin{tabular}{rccccccccc}
\hline $\mathrm{pH}$ & $\mathrm{P}(\mathrm{Mel})$ & $\mathrm{K}$ & $\mathrm{Ca}$ & $\mathrm{Mg}$ & $\mathrm{Al}$ & $\mathrm{H}+\mathrm{Al}$ & $\mathrm{CTC}$ & $\mathrm{V}$ & $\mathrm{MO}$ \\
\hline $\mathrm{CaCl}_{2}$ & $\mathrm{mg} \mathrm{dm}^{-3}$ & & & & $\mathrm{cmol}_{\mathrm{c}} \mathrm{dm}^{-3--}$ & & & $\%$ & $\mathrm{~g} \mathrm{dm}^{-3}$ \\
\hline 4,9 & 5,5 & 0,13 & 1,7 & 0,7 & 0,1 & 6,0 & 8,6 & 54,53 & 46,8 \\
\hline
\end{tabular}

$O$ delineamento experimental utilizado foi em blocos casualizados, no esquema fatorial $3 \times 5$, com um tratamento adicional (testemunha), totalizando dezesseis tratamentos. Os fatores consistiram em três doses de cama de aves $(2,5 \mathrm{e}$ $\left.8 \mathrm{Mg} \mathrm{ha}^{-1}\right)$ e cinco doses de nitrogênio $(0,50,100$,
150, $200 \mathrm{~kg} \mathrm{ha-1}$ ). A testemunha recebeu fertilizante mineral a lanço na semeadura nas doses de 120,80 e $20 \mathrm{~kg} \mathrm{ha}^{-1}$ de $\mathrm{P}_{2} \mathrm{O}_{5}, \mathrm{~K}_{2} \mathrm{O}$ e N, respectivamente e cobertura com $200 \mathrm{~kg} \mathrm{ha}^{-1} \mathrm{de}$ N. A adubação da testemunha foi definida de acordo com a análise química do solo e a 
produtividade esperada da cultura. Foram utilizadas quatro repetições, totalizando 64 parcelas de 5,0 $\mathrm{m}$ de comprimento e cinco linhas espaçadas a $0,45 \mathrm{~m}$.

O preparo da área foi realizado com aplicação do herbicida glyphosate em préemergência, na dose de $4 \mathrm{~L} \mathrm{ha}^{-1}$ de produto comercial, aproximadamente 15 dias antes da semeadura em todos os anos. No primeiro ano foi utilizado o híbrido $2 \mathrm{~B} 512 \mathrm{HX}$ e nos anos subsequentes o híbrido $30 \mathrm{~F} 53 \mathrm{H}$. As semeaduras foram realizadas no mês de novembro utilizando uma semeadora de 5 linhas, espaçadas de $45 \mathrm{~cm}$. A população final esperada por hectare foi de 65.000 plantas. Após a semeadura distribuiu-se nas parcelas a cama de aves, cuja concentração era de 30,$7 ; 28,6$ e $34,7 \mathrm{~g} \mathrm{~kg}^{-1}$ de $\mathrm{N}, \mathrm{P}_{2} \mathrm{O}_{5}$ e $\mathrm{K}_{2} \mathrm{O}$ respectivamente. $\mathrm{O}$ controle de plantas daninhas e o manejo fitossanitário seguiram as recomendações para a cultura na região. Realizou-se adubação nitrogenada em cobertura, com as plantas de milho no estádio V4.

Determinou-se o Índice de clorofila Falker (ICF) para clorofila total por meio do medidor eletrônico ClorofiLOG CFL 1030 (FALKER, 2008).

A medição de altura e a primeira leitura do ICF ocorreu no estádio V6 nos dois primeiros anos de cultivo. Na safra 2013/14 a medição da altura de plantas foi realizada no estádio $\mathrm{V} 6 \mathrm{e}$ primeira leitura de ICF no estádio V8. No início do pendoamento realizou-se nova leitura de ICF. Posteriormente, realizou-se a medição da altura de inserção de espiga.
Para o cálculo da produtividade e massa de cem grãos a umidade dos grãos colhidos foi corrigida para $14 \%$.

Os resultados foram submetidos à análise de variância e análises complementares. A testemunha foi comparada com os demais tratamentos utilizando teste de Dunnet ao nível de $5 \%$ de probabilidade (bilateral) utilizando-se o programa computacional Estat (BARBOSA et al., 1992). Os efeitos das doses de cama de aves e de nitrogênio foram avaliados por meio de análise de regressão utilizando-se o programa computacional R (R CORE TEAM, 2018) e o pacote ExpDes.pt (FERREIRA et al., 2018).

\section{RESULTADOS E DISCUSSÃO}

Os resultados da análise de variância mostraram, pelo teste $F$, efeito significativo para as doses de cama de aves em relação às variáveis ICF, altura de plantas e altura de espigas nos três anos de cultivo, enquanto que as doses de nitrogênio apresentaram efeito significativo resposta somente em termos de altura de plantas nos dois últimos anos de cultivo.

Observa-se que para ICF em V6 nos dois primeiros anos de cultivo, os tratamentos que não receberam $\mathrm{N}$ em cobertura apresentaram valores mais baixos, enquanto que no terceiro ano, para ICF no estádio V8 apenas o tratamento $2 \mathrm{Mg} \mathrm{ha}^{-1}$ sem cobertura nitrogenada foi inferior aos demais (Tabela 1). 
Tabela 1. Teste de Dunnet para ICF no estádio V6 (LCV6) e V8 (LCV8), ICF no estádio Vt (LCVt), em função de doses de cama de aves (CA) e nitrogênio (N) em cobertura. Comparação entre os tratamentos do fatorial e a testemunha com adubação química (QUI). Jataí, GO, Safras 2011/2012, 2012/2013 e 2013/2014.

\begin{tabular}{cccccccc}
\hline \multirow{2}{*}{ CA } & \multirow{2}{*}{$\mathrm{N}$} & \multicolumn{2}{c}{$2011 / 2012$} & \multicolumn{2}{c}{$2012 / 2013$} & \multicolumn{2}{c}{$2013 / 2014$} \\
\cline { 3 - 7 } & & LcV6 & LcVt & LcV6 & LcVt & LCV8 & LcVt \\
\hline 2 & 0 & $61,70 \mathrm{~b}$ & $59,55 \mathrm{a}$ & $51,53 \mathrm{~b}$ & $54,50 \mathrm{~b}$ & $59,55 \mathrm{~b}$ & $56,53 \mathrm{~b}$ \\
5 & 0 & $60,90 \mathrm{~b}$ & $61,54 \mathrm{a}$ & $56,52 \mathrm{~b}$ & $61,11 \mathrm{~b}$ & $63,70 \mathrm{a}$ & $60,50 \mathrm{~b}$ \\
8 & 0 & $62,84 \mathrm{~b}$ & $65,17 \mathrm{a}$ & $56,53 \mathrm{~b}$ & $61,97 \mathrm{a}$ & $65,00 \mathrm{a}$ & $64,66 \mathrm{a}$ \\
2 & 50 & $65,59 \mathrm{a}$ & $60,58 \mathrm{a}$ & $58,90 \mathrm{a}$ & $61,88 \mathrm{a}$ & $63,14 \mathrm{a}$ & $60,91 \mathrm{~b}$ \\
5 & 50 & $65,65 \mathrm{a}$ & $65,85 \mathrm{a}$ & $60,13 \mathrm{a}$ & $63,26 \mathrm{a}$ & $66,05 \mathrm{a}$ & $63,66 \mathrm{a}$ \\
8 & 50 & $64,32 \mathrm{a}$ & $65,98 \mathrm{a}$ & $58,20 \mathrm{a}$ & $65,69 \mathrm{a}$ & $66,21 \mathrm{a}$ & $64,59 \mathrm{a}$ \\
2 & 100 & $65,97 \mathrm{a}$ & $64,26 \mathrm{a}$ & $59,19 \mathrm{a}$ & $63,65 \mathrm{a}$ & $65,14 \mathrm{a}$ & $64,27 \mathrm{a}$ \\
5 & 100 & $65,34 \mathrm{a}$ & $64,52 \mathrm{a}$ & $58,77 \mathrm{a}$ & $67,67 \mathrm{a}$ & $66,43 \mathrm{a}$ & $67,05 \mathrm{a}$ \\
8 & 100 & $67,45 \mathrm{a}$ & $67,86 \mathrm{a}$ & $58,40 \mathrm{a}$ & $65,44 \mathrm{a}$ & $67,57 \mathrm{a}$ & $67,12 \mathrm{a}$ \\
2 & 150 & $68,09 \mathrm{a}$ & $68,80 \mathrm{a}$ & $58,55 \mathrm{a}$ & $65,39 \mathrm{a}$ & $63,32 \mathrm{a}$ & $65,18 \mathrm{a}$ \\
5 & 150 & $65,97 \mathrm{a}$ & $66,91 \mathrm{a}$ & $60,74 \mathrm{a}$ & $67,16 \mathrm{a}$ & $67,61 \mathrm{a}$ & $66,85 \mathrm{a}$ \\
8 & 150 & $66,25 \mathrm{a}$ & $66,92 \mathrm{a}$ & $60,97 \mathrm{a}$ & $65,56 \mathrm{a}$ & $67,31 \mathrm{a}$ & $66,75 \mathrm{a}$ \\
2 & 200 & $67,09 \mathrm{a}$ & $67,27 \mathrm{a}$ & $58,09 \mathrm{a}$ & $66,94 \mathrm{a}$ & $66,49 \mathrm{a}$ & $65,90 \mathrm{a}$ \\
5 & 200 & $67,54 \mathrm{a}$ & $66,28 \mathrm{a}$ & $59,61 \mathrm{a}$ & $68,92 \mathrm{a}$ & $66,31 \mathrm{a}$ & $67,05 \mathrm{a}$ \\
8 & 200 & $67,72 \mathrm{a}$ & $67,16 \mathrm{a}$ & $59,09 \mathrm{a}$ & $66,72 \mathrm{a}$ & $66,70 \mathrm{a}$ & $65,46 \mathrm{a}$ \\
& QUI & $66,55 \mathrm{a}$ & $64,31 \mathrm{a}$ & $59,55 \mathrm{a}$ & $66,03 \mathrm{a}$ & $65,60 \mathrm{a}$ & $67,03 \mathrm{a}$ \\
\hline \multicolumn{2}{c}{ CV (\%) } & 1,85 & 3,59 & 2,22 & 3,43 & 3,37 & 3,41 \\
\hline
\end{tabular}

Médias seguidas por letras iguais na coluna não diferem entre si pelo teste de Dunnet a $5 \%$ de probabilidade.

Esses resultados demonstram que com o passar dos anos, a cama de aves contribuiu gradativamente com a disponibilização de nitrogênio para o milho. Segundo Rambo et al. (2011), os índices de clorofila estão fortemente correlacionados com a nutrição das plantas em termos de nitrogênio e consequentemente produtividade. A concentração das clorofilas (a e b) correlaciona-se positivamente com 0 nitrogênio foliar e influencia a taxa fotossintética (RUTTANAPRASERT et al., 2012). Uma planta com suprimento adequado de nitrogênio apresenta cloroplastos maiores, com mais membranas tilacóides e menor proporção de estroma em relação à uma planta com deficiência de $\mathrm{N}$ (PRADO et al., 2007).

No estádio $\mathrm{Vt}$, apenas o segundo e terceiro anos de cultivo apresentaram diferenças entre os tratamentos e a testemunha para ICF (Tabela 1). Observa-se que no primeiro ano, provavelmente, os teores de nitrogênio presentes no solo provenientes do plantio direto contribuíram satisfatoriamente para o desenvolvimento da cultura, enquanto que no segundo ano os tratamentos que não receberam nitrogênio em cobertura mostraram-se inferiores à testemunha. O uso do sistema de plantio direto resulta no aumento dos teores de matéria orgânica no solo (BAYER; SCHENEIDER, 1999) que disponibiliza N para as plantas, mas com os cultivos sucessivos sem a reposição dos nutrientes exportados pode ter levado à redução da produtividade. Fornasieri Filho (1992) mostra que, em solos com teores não limitantes de matéria orgânica com pluviosidade adequada, os efeitos da adubação nitrogenada são pouco pronunciados.

Já no terceiro ano, mesmo a utilização de 2 $\mathrm{Mg} \mathrm{ha}{ }^{-1}$ associada a $50 \mathrm{~kg} \mathrm{ha}^{-1}$ de $\mathrm{N}$ em cobertura não foi suficiente para atender a necessidade do milho devido ao uso das reservas de $\mathrm{N}$ provenientes do solo ao longo do tempo. Porém, a utilização da dose de $8 \mathrm{Mg} \mathrm{ha}^{-1}$ mesmo sem cobertura nitrogenada foi suficiente para atender as exigências do milho neste estádio, o que evidencia a disponibilização a longo prazo do nitrogênio proveniente da cama de aviário (Tabela 1). Balbinot Júnior et al. (2012) ressaltam - efeito residual da cama de aviário na produtividade do consórcio de aveia-preta + ervilhaca e milheto em sucessão.

Os resultados do teste de Dunnet para altura de plantas em V6 nas safras 2011/2012 e V8 na safra 2012/2013 e altura de espigas para os três anos são apresentados na Tabela 2. Para a 
altura de plantas, no primeiro ano de cultivo, não houve diferença entre os tratamentos e a testemunha, porém, no ano seguinte a menor dose de cama de aves associada a 0 e $200 \mathrm{~kg} \mathrm{ha}^{-1}$ de $\mathrm{N}$ proporcionaram altura inferiores, enquanto que no terceiro ano a maior dose de cama de aves associada a 0, 50 e $100 \mathrm{~kg} \mathrm{ha}^{-1}$ de nitrogênio proporcionaram alturas superiores a testemunha (Tabela 2). Isso demonstra que a altura de plantas parece estar mais relacionada a outros nutrientes que não o nitrogênio, entretanto, assim como este, aqueles elementos são disponibilizados para a cultura ao longo do tempo devido à necessidade mineralização do composto orgânico (PEIXOTO FILHO et al., 2013). Medeiros et al. (2008) observaram efeito da relação $\mathrm{Ca}: \mathrm{Mg}$ do corretivo sobre a altura de plantas de milho. Valderrama et al. (2011) afirmam que a resposta da altura de plantas de milho à aplicação de $\mathrm{N}$ é dependente do histórico da área, condições climáticas e estádios de aplicação do nitrogênio.

Tabela 2. Teste de Dunnet para altura de plantas no estádio V6 (Altp) e altura de espigas (Altesp), em função de doses de cama de aves (CA) e nitrogênio (N) em cobertura. Comparação entre os tratamentos do fatorial e a testemunha com adubação química (QUI). Jataí, GO, Safras 2011/2012, 2012/2013 e 2013/2014.

\begin{tabular}{cccccccc}
\hline \multirow{2}{*}{ CA } & \multirow{2}{*}{$\mathrm{N}$} & \multicolumn{2}{c}{$2011 / 2012$} & \multicolumn{2}{c}{$2012 / 2013$} & \multicolumn{2}{c}{$2013 / 2014$} \\
\cline { 3 - 7 } & & Altp (cm) & Altesp (cm) & Altp (cm) & Altesp (cm) & Altp (cm) & Altesp (cm) \\
\hline 2 & 0 & $70,90 \mathrm{a}$ & $126,05 \mathrm{a}$ & $21,62 \mathrm{~b}$ & $115,82 \mathrm{a}$ & $24,55 \mathrm{~b}$ & $111,47 \mathrm{a}$ \\
5 & 0 & $78,10 \mathrm{a}$ & $128,35 \mathrm{a}$ & $24,70 \mathrm{a}$ & $113,15 \mathrm{a}$ & $27,57 \mathrm{~b}$ & $118,00 \mathrm{a}$ \\
8 & 0 & $84,30 \mathrm{a}$ & $130,67 \mathrm{a}$ & $25,62 \mathrm{a}$ & $114,60 \mathrm{a}$ & $30,35 \mathrm{a}$ & $120,50 \mathrm{a}$ \\
2 & 50 & $73,25 \mathrm{a}$ & $126,15 \mathrm{a}$ & $24,15 \mathrm{a}$ & $112,97 \mathrm{a}$ & $23,90 \mathrm{~b}$ & $111,95 \mathrm{a}$ \\
5 & 50 & $85,30 \mathrm{a}$ & $131,37 \mathrm{a}$ & $26,25 \mathrm{a}$ & $117,40 \mathrm{a}$ & $27,97 \mathrm{~b}$ & $117,82 \mathrm{a}$ \\
8 & 50 & $86,05 \mathrm{a}$ & $130,45 \mathrm{a}$ & $25,80 \mathrm{a}$ & $113,97 \mathrm{a}$ & $29,60 \mathrm{a}$ & $118,77 \mathrm{a}$ \\
2 & 100 & $76,12 \mathrm{a}$ & $126,85 \mathrm{a}$ & $23,22 \mathrm{a}$ & $118,35 \mathrm{a}$ & $23,87 \mathrm{~b}$ & $111,40 \mathrm{a}$ \\
5 & 100 & $84,00 \mathrm{a}$ & $137,15 \mathrm{a}$ & $24,70 \mathrm{a}$ & $117,07 \mathrm{a}$ & $28,10 \mathrm{~b}$ & $117,12 \mathrm{a}$ \\
8 & 100 & $84,70 \mathrm{a}$ & $133,42 \mathrm{a}$ & $25,95 \mathrm{a}$ & $112,25 \mathrm{a}$ & $29,55 \mathrm{a}$ & $122,10 \mathrm{a}$ \\
2 & 150 & $79,67 \mathrm{a}$ & $128,82 \mathrm{a}$ & $23,75 \mathrm{a}$ & $113,35 \mathrm{a}$ & $22,70 \mathrm{a}$ & $106,85 \mathrm{~b}$ \\
5 & 150 & $82,17 \mathrm{a}$ & $133,45 \mathrm{a}$ & $25,02 \mathrm{a}$ & $119,87 \mathrm{a}$ & $26,02 \mathrm{~b}$ & $120,40 \mathrm{a}$ \\
8 & 150 & $84,92 \mathrm{a}$ & $132,70 \mathrm{a}$ & $26,02 \mathrm{a}$ & $120,22 \mathrm{a}$ & $28,25 \mathrm{~b}$ & $123,55 \mathrm{a}$ \\
2 & 200 & $74,72 \mathrm{a}$ & $124,37 \mathrm{a}$ & $22,55 \mathrm{~b}$ & $108,37 \mathrm{a}$ & $23,60 \mathrm{~b}$ & $110,20 \mathrm{a}$ \\
5 & 200 & $80,90 \mathrm{a}$ & $134,52 \mathrm{a}$ & $24,02 \mathrm{a}$ & $107,45 \mathrm{a}$ & $27,40 \mathrm{~b}$ & $120,75 \mathrm{a}$ \\
8 & 200 & $83,87 \mathrm{a}$ & $132,27 \mathrm{a}$ & $23,85 \mathrm{a}$ & $116,12 \mathrm{a}$ & $28,30 \mathrm{~b}$ & $121,20 \mathrm{a}$ \\
& QU & $78,77 \mathrm{a}$ & $130,60 \mathrm{a}$ & $25,52 \mathrm{a}$ & $114,60 \mathrm{a}$ & $25,65 \mathrm{~b}$ & $117,40 \mathrm{a}$ \\
\hline \multicolumn{2}{c}{ CV (\%) } & 5,15 & 3,72 & 4,95 & 3,06 & 4,93 & 3,69 \\
\hline
\end{tabular}

Média seguidas por letras iguais na coluna não diferem entre si pelo teste de Dunnet a 5\% de probabilidade.

Para altura de espigas (Tabela 2), exceto o tratamento $2 \mathrm{Mg} \mathrm{ha}^{-1}$ associado a $150 \mathrm{~kg} \mathrm{ha}^{-1}$ de $\mathrm{N}$, todos os tratamentos nos três anos de cultivo foram semelhantes a testemunha, uma vez que é uma característica mais influenciada pela genética do que pelo ambiente (PAIXÃO et al., 2008).

Com relação a produtividade e massa de 100 grãos, para os fatores nitrogênio e cama de aves, houve efeito dos tratamentos, exceto para a massa de 100 grãos no último ano de cultivo para o fator nitrogênio. A interação entre as doses de nitrogênio e cama de aves mostraram efeito significativo para a segunda avaliação de clorofila nos dois primeiros anos. Enquanto que para a primeira avaliação de ICF somente o segundo ano de cultivo apresentou interação significativa (Tabela 3). 
Tabela 3. Teste de Dunnet para massa de 100 grãos (M100g) e produtividade (Prod) do milho, em função de doses de cama de aves (CA) e nitrogênio $(\mathrm{N})$ em cobertura. Comparação entre os tratamentos do fatorial e a testemunha com adubação química (QUI) Jataí, GO, Safras 2011/2012, 2012/2013 e 2013/2014.

\begin{tabular}{|c|c|c|c|c|c|c|c|}
\hline \multirow{2}{*}{ CA } & \multirow{2}{*}{$\mathrm{N}$} & \multicolumn{2}{|c|}{$2011 / 2012$} & \multicolumn{2}{|c|}{$2012 / 2013$} & \multicolumn{2}{|c|}{$2013 / 2014$} \\
\hline & & M100g & Prod & M100g & Prod & $\mathrm{M} 100 \mathrm{~g}$ & Prod \\
\hline 2 & 0 & $32,13 b$ & 9423,50 a & $32,23 \mathrm{~b}$ & 7251,85 b & $30,49 \mathrm{~b}$ & 6319,76 b \\
\hline 5 & 0 & $32,41 b$ & 10302,72 b & $34,38 a$ & 9509,78 a & $32,49 a$ & 8126,70 a \\
\hline 8 & 0 & 33,78 a & 10985,24 b & $35,20 \mathrm{a}$ & $10266,21 \mathrm{a}$ & $34,67 \mathrm{a}$ & $10393,50 \mathrm{a}$ \\
\hline 2 & 50 & $33,04 \mathrm{~b}$ & 10098,64 b & $32,08 \mathrm{~b}$ & 9394,27 a & $29,50 \mathrm{~b}$ & 7369,63 b \\
\hline 5 & 50 & $34,94 \mathrm{a}$ & $11663,17 \mathrm{~b}$ & $36,03 \mathrm{a}$ & $10336,02 \mathrm{a}$ & $32,07 \mathrm{a}$ & 9378,84 a \\
\hline 8 & 50 & $34,76 \mathrm{a}$ & $11767,44 b$ & $37,62 \mathrm{a}$ & $10826,95 \mathrm{a}$ & 35,98 a & 10903,45 a \\
\hline 2 & 100 & $33,85 \mathrm{a}$ & $11713,50 \mathrm{~b}$ & $33,37 \mathrm{a}$ & 9658,94 a & $31,45 \mathrm{a}$ & 7150,56 b \\
\hline 5 & 100 & $34,55 \mathrm{a}$ & 12037,64 b & $36,26 \mathrm{a}$ & 10935,93 a & $35,21 \mathrm{a}$ & 9680,71 a \\
\hline 8 & 100 & $35,51 \mathrm{a}$ & 12478,35 b & $36,13 \mathrm{a}$ & $10735,55 a$ & $34,42 \mathrm{a}$ & $9751,30 \mathrm{a}$ \\
\hline 2 & 150 & $34,64 \mathrm{a}$ & $11394,71 b$ & $33,86 a$ & $10312,96 \mathrm{a}$ & $30,15 \mathrm{~b}$ & 7690,58 b \\
\hline 5 & 150 & 35,36 a & $11611,03 \mathrm{~b}$ & $36,69 a$ & $10361,43 a$ & $33,97 a$ & 9438,39 a \\
\hline 8 & 150 & $35,53 \mathrm{a}$ & $12878,20 \mathrm{a}$ & $37,30 \mathrm{a}$ & $11773,04 \mathrm{a}$ & $35,76 a$ & $10795,75 a$ \\
\hline 2 & 200 & 33,71 a & $11376,39 \mathrm{~b}$ & $34,29 a$ & $10904,04 \mathrm{a}$ & $30,73 \mathrm{~b}$ & 7900,11 b \\
\hline 5 & 200 & 35,84 a & $12619,41 \mathrm{a}$ & $37,78 \mathrm{a}$ & $10949,70 \mathrm{a}$ & $34,12 \mathrm{a}$ & 10261,78 a \\
\hline 8 & 200 & 36,15 a & $12735,06 \mathrm{a}$ & $37,48 a$ & $11796,78 a$ & $35,15 a$ & $10292,05 \mathrm{a}$ \\
\hline \multicolumn{2}{|c|}{ QUI } & 35,25 a & $11077,09 \mathrm{~b}$ & $35,66 \mathrm{a}$ & $10342,00 \mathrm{a}$ & $34,18 \mathrm{a}$ & 9506,88 a \\
\hline \multicolumn{2}{|c|}{ CV (\%) } & 3,06 & 5,90 & 3,89 & 7,34 & 4,37 & 7,78 \\
\hline
\end{tabular}

Média seguidas por letras iguais na coluna não diferem entre si pelo teste de Dunnet a $5 \%$ de probabilidade.

Os tratamentos que não receberam nitrogênio em cobertura, exceto aquele com 8 Mg ha ${ }^{-1}$ de cama de aves sem cobertura nitrogenada, e o tratamento $2 \mathrm{Mg} \mathrm{ha}^{-1}$ de cama associado a $50 \mathrm{~kg} \mathrm{ha}^{-1}$ de $\mathrm{N}$, não proporcionaram nutrição adequada à cultura do milho para que a massa de 100 grãos fosse semelhante a testemunha na safra 2011/2012 (Tabela 3). Já no segundo ano a resposta foi semelhante, porém a dose de $5 \mathrm{Mg} \mathrm{ha}^{-1}$ com 0 de $\mathrm{N}$ foi igual a testemunha. No terceiro ano de cultivo as doses de $2 \mathrm{Mg} \mathrm{ha}{ }^{-1}$, exceto com $100 \mathrm{~kg} \mathrm{ha}^{-1}$ de $\mathrm{N}$ foram inferiores a testemunha, demonstrando a deficiência nutricional nesses tratamentos.

Em termos de produtividade observa-se que o milho nos dois primeiros anos de cultivo produziu menos quando recebeu $2 \mathrm{Mg} \mathrm{ha}^{-1}$ de cama de aves sem nitrogênio em cobertura, quando comparado a testemunha (Tabela 3). No terceiro ano observa-se que todos os tratamentos que receberam a dose mencionada foram inferiores à testemunha, demonstrando que essa dose de cama de aves não é suficiente para repor a quantidade de nutrientes extraídos ao longo dos anos pela cultura do milho.

A cama de aves necessita de certo período de tempo para que com as reações de decomposição, mineralização e imobilização de nutrientes pela microbiota do solo, os nutrientes sejam disponibilizados, como ressalta Valadão et al. (2011), especialmente o N. Infere-se que a disponibilização deste elemento possa ser mais tardia e influencie principalmente a massa de grãos. Porém, o ganho de produtividade não foi comprometido pelo atraso no fornecimento de alguns nutrientes. Bono e Felini (2011) ressaltam o efeito residual da cama de aves nas culturas da soja e do milho. Os mesmos autores encontraram efeitos para produtividade com aumento das doses de cama de aves até $8 \mathrm{Mg} \mathrm{ha}^{-1}$.

Pela análise da cama de aves na dose $2 \mathrm{Mg}$ $\mathrm{ha}^{-1}$ seriam fornecidos somente $61,4,57,2$ e 69,4 $\mathrm{kg} \mathrm{ha}^{-1}$ de $\mathrm{N}, \mathrm{P}_{2} \mathrm{O}_{5}$ e $\mathrm{K}_{2} \mathrm{O}$, respectivamente. Por isso era esperado que nestes tratamentos houvesse uma diminuição da produtividade devido ao uso de parte das reservas nutricionais do solo ao longo dos anos, pois a dose de $2 \mathrm{Mg}$ ha $^{-1}$ não possibilita $\mathrm{o}$ suprimento das necessidades do milho em produção de alta tecnologia. Segundo Maggio (2006) a cultura do milho pode absorver até $23,5 \mathrm{~kg}$ de $\mathrm{N}$ para cada $\mathrm{Mg}$ de grãos verdes. Silva et al. (2006) 
encontraram média de exportação de nitrogênio de 15,7 kg por cada Mg de grãos de milho.

As equações de regressão significativas em função das doses de nitrogênio para ICF nas safras 2011/2012, 2012/2013 e 2013/2014 são apresentadas na Figura 1. Quando houve interação significativa entre os fatores cama de aves e $\mathrm{N}$ procedeu-se ao desdobramento. A resposta da primeira avaliação de ICF, em V6 e V8, foi quadrática nos três anos (Figuras $1 \mathrm{~A}, 1 \mathrm{C}$ e 1D).

Figura 1. Índice de Clorofila Falker (ICF) no estádio V6 safra 2011/12 (A), estádio Vt safra 2011/12 (B), estádio V6 safra 2012/13 (C), estádio Vt safra 2012/13 (D), estádio V8 safra 2013/14 (E), estádio Vt safra 2013/14 (F). Desdobramento realizado quando houve interação significativa com o fator Cama de Aves (CA).
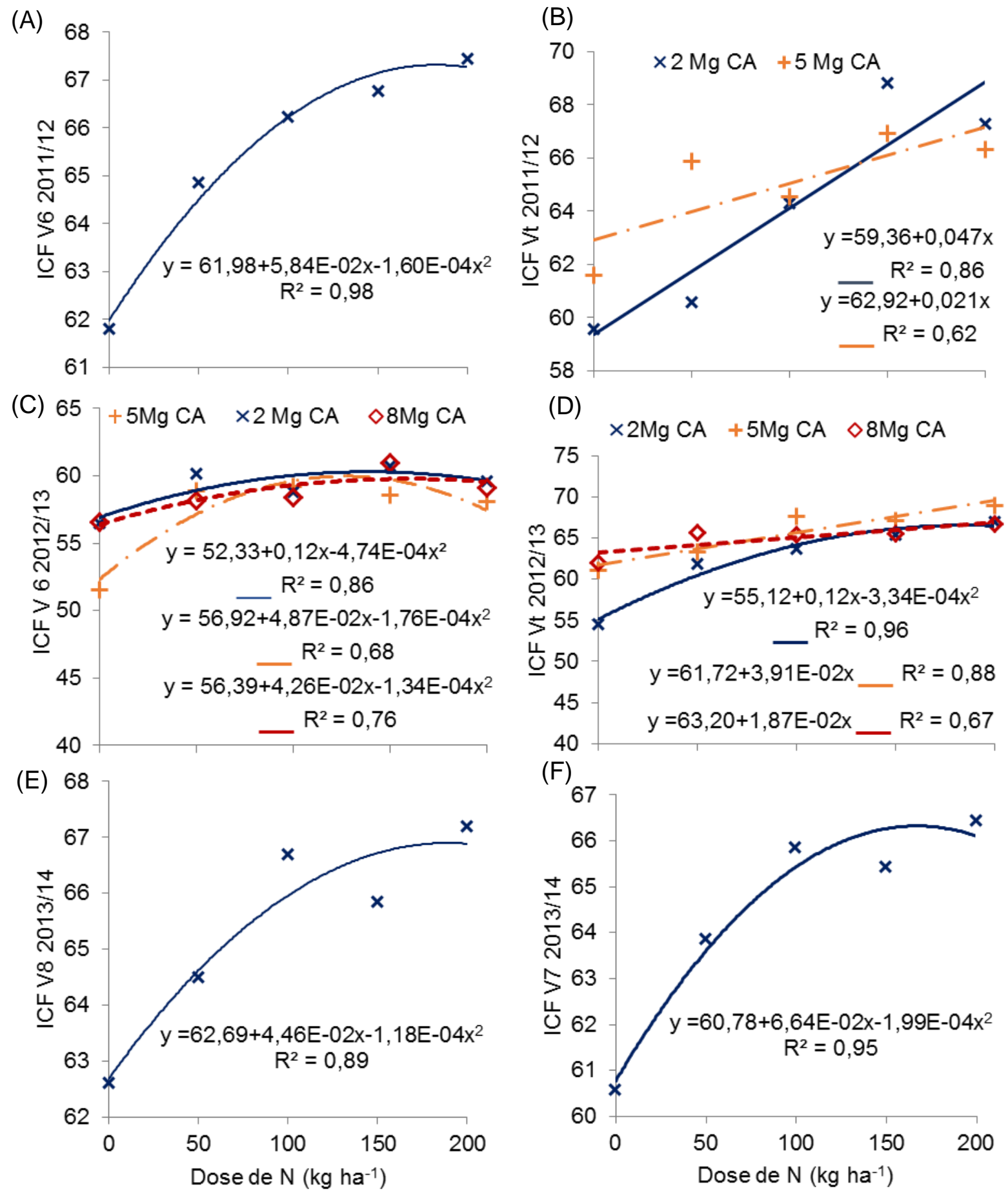
Esse resultado evidencia que a quantidade de $\mathrm{N}$ fornecidos nas maiores doses foi superior às exigências das plantas em estádio pouco avançado, que não necessitariam de doses elevadas para suprir as suas exigências para produção de clorofila. De acordo com os modelos ajustados, os valores máximos de ICF seriam obtidos nas doses de 182,6 e $189,1 \mathrm{~kg} \mathrm{ha}^{-1}$ nas safras 2011/2012 e 2013/2014 respectivamente, para as médias com as três doses de cama de aves. Já para a safra 2012/2013 como houve interação significativa, os máximos de ICF em V6 seriam obtidos com as doses de 126,9, 138,6 e $158,5 \mathrm{~kg} \mathrm{ha}^{-1}$ de $\mathrm{N}$ para as doses de 2, 5 e $8 \mathrm{Mg}$ $\mathrm{ha}^{-1}$ de cama de aves. Segundo Hurtado et al. (2010), a dose de $100 \mathrm{~kg} \mathrm{ha}^{-1}$ de $\mathrm{N}$ é suficiente para atender às exigências do milho no estádio V4, porém após esse estádio de desenvolvimento essa dose não proporciona o máximo de clorofila total para a cultura.

Para ICF no estádio Vt, no primeiro ano, a resposta ao aumento crescente das doses de nitrogênio é linear (Figura $1 \mathrm{~B}$ ). No segundo ano (Figura $1 \mathrm{D}$ ), a resposta foi quadrática para a dose $2 \mathrm{Mg} \mathrm{ha}^{-1}$ possivelmente em virtude da limitação de outros nutrientes que afetaram a resposta da cultura às doses de $\mathrm{N}$, como por exemplo o potássio (K).O máximo de clorofila nesse estádio, segundo o modelo ajustado seria obtido com a dose de $166,8 \mathrm{~kg} \mathrm{ha}{ }^{-1}$ de $\mathrm{N}$. O suprimento adequado de $\mathrm{N}$ e $\mathrm{K}$ frequentemente aumenta a resposta de ambos, e a não adição de um deles pode levar a decréscimos da resposta do outro (NOVAES et al., 2007). Na maior dose (8 $\mathrm{Mg} \mathrm{ha}^{-1}$ ) a cultura responde de forma menos acentuada ao aumento da dose de nitrogênio quando comparada a dose $5 \mathrm{Mg} \mathrm{ha}^{-1}$, provavelmente pela disponibilização do $\mathrm{N}$ imobilizado pela microbiota do solo pela adição do resíduo. No terceiro ano de cultivo a equação de regressão da clorofila no estádio Vt obedeceu ao modelo quadrático (Figura $1 \mathrm{~F}$ ), o que demonstra aumentos decrescentes em termos dessa variável ao aumento da adubação nitrogenada.

A altura de plantas em V6 respondeu diferente no segundo e terceiro ano, obedecendo aos modelos quadrático e linear, respectivamente (Figuras $2 \mathrm{~A}$ e $2 \mathrm{~B}$ ), enquanto que a altura de espigas não se adequou a nenhum modelo. A máxima altura, de acordo com o modelo ajustado, seria obtida com a dose de 88,9 $\mathrm{kg} \mathrm{ha}^{-1}$ de $\mathrm{N}$ na safra 2012/2013. Soratto et al. (2010), porém observou incremento linear para a altura de plantas e nenhuma resposta em altura de espigas ao aumento da dose de $\mathrm{N}$ no milho safrinha.

Figura 2. Altura de plantas de milho no estádio V6 safra 2012/13 (A) e safra 2013/14 (B).
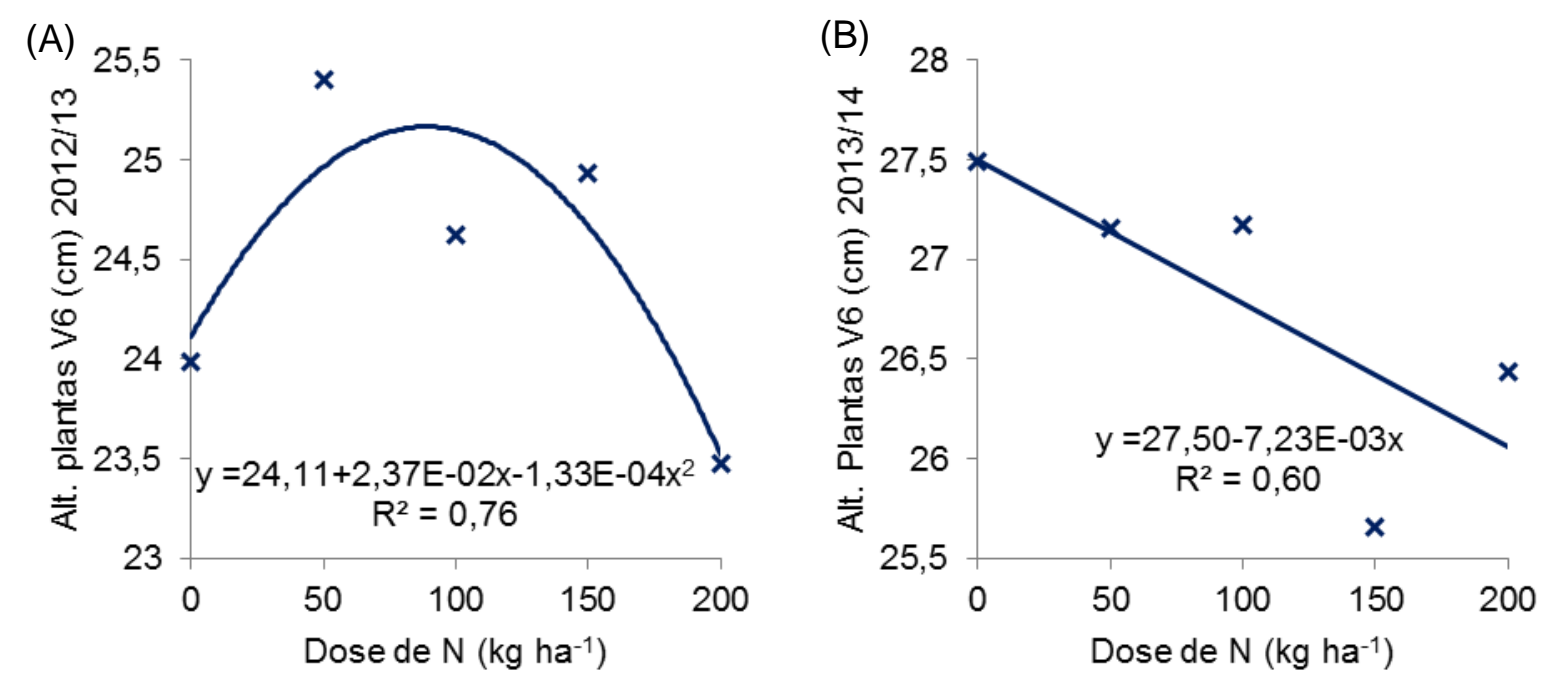

A produtividade e a massa de 100 grãos ajustaram-se ao modelo quadrático no primeiro ano (Figuras 3A e 3D), semelhante ao encontrado por Bastos et al. (2008). A máxima produtividade seria obtida, de acordo com o modelo ajustado na dose de $172,1 \mathrm{~kg} \mathrm{ha}^{-1}$ de $\mathrm{N}$. Para a massa de
100 grãos o valor máximo seria obtido na dose de $176,3 \mathrm{~kg} \mathrm{ha}^{-1}$ de N. Para as mesmas variáveis nos anos seguintes houve ajuste ao modelo linear, o qual as maiores doses de $\mathrm{N}$ propiciaram maiores produtividade (Figuras 3B, 3C e 3D). Valderrama et al. (2011) atribuem o efeito positivo do $\mathrm{N}$ 
sobre a produtividade pelo aumento linear do teor $\mathrm{N}$ foliar, e do número de espigas por hectare. A adequada nutrição da planta em $\mathrm{N}$ resulta em maior crescimento da área foliar e do sistema radicular, pois favorece a divisão, a expansão celular e a fotossíntese (Varvel et al., 1997).

Figura 3. Produtividade de grãos nas safras 2011/12 (A), safra 2012/13 (B) e safra 2013/14 (C) e massa de 100 grãos nas safras 2011/12 e 2012/13 (D).

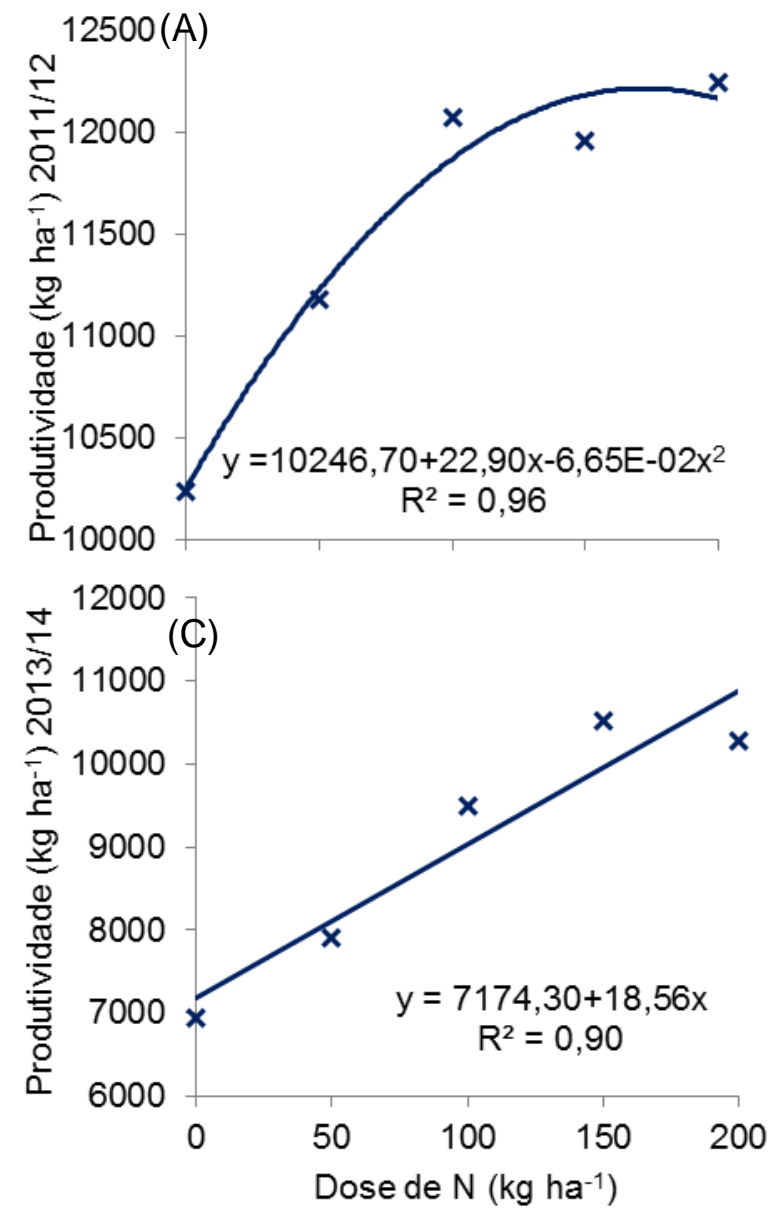

Esperava-se resposta semelhante entre estas variáveis visto que a produtividade está intimamente relacionada com a massa dos grãos. Bono e Felini (2011) observaram incrementos decrescentes em termos de produtividade do milho ao aumento da dose de cama de aviário. Resultados semelhantes foram encontrados por Soratto et al. (2011), nos quais o aumento da dose do fertilizante nitrogenado propicia aumento linear em termos de produtividade.

Pode-se inferir que após o início dos estádios reprodutivos, as plantas podem ainda ter assimiliado quantidades consideráveis de $\mathrm{N}$ que posteriormente resultam em maior enchimento de grãos, pois decréscimos na concentração de nitrogênio no período de enchimento dos grãos pode ocasionar reflexos negativos (RIZZARDI et al., 2008).

Com o efeito linear para produtividade
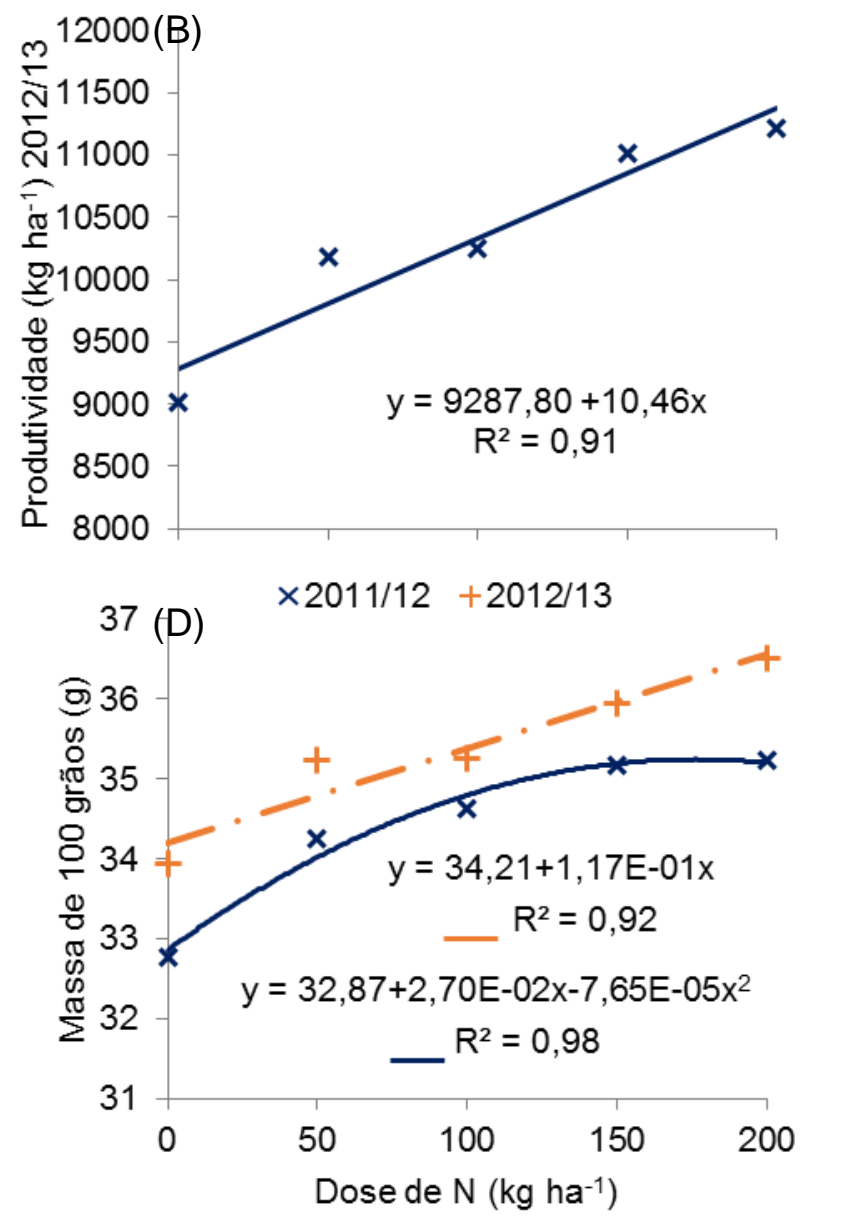

também se pode inferir que o milho mesmo recebendo elevadas doses de $\mathrm{N}$ orgânico através da cama de aves necessita de complementação com $\mathrm{N}$ mineral quando se objetiva altas produtividades. No processo de mineralização da cama de aves alguns nutrientes como o $\mathrm{N}$ são imobilizados temporariamente pelos microrganismos do solo, e esse processo é dependente de diversos fatores como condições aeróbicas, umidade do solo, temperatura e $\mathrm{pH}$ (NOVAES et al., 2007).

\section{CONCLUSÕES}

1. O aumento do teor de clorofila está diretamente relacionado ao aumento da dose de $\mathrm{N}$, tanto na forma orgânica quanto mineral.

2. A disponibilização mais intensa de $\mathrm{N}$ da cama de aves ocorre em estádios mais 
avançados da cultura do milho.

3. As maiores doses de cama de aves utilizadas (5 e $8 \mathrm{Mg} \mathrm{ha}^{-1}$ ) em três anos sucessivos, mesmo sem $\mathrm{N}$ em cobertura, propicia produtividade semelhante à testemunha com fertilizante mineral na cultura do milho, sendo assim, a cama de aves é alternativa viável na adubação da cultura do milho a longo prazo.

\section{AGRADECIMENTOS}

Ao Conselho Nacional de Desenvolvimento Científico e Tecnológico (CNPq) pelo financiamento do projeto e bolsa de iniciação científica do primeiro autor.

\section{REFERÊNCIAS}

BALBINOT JÚNIOR, A. A.; HANISCH, A. L.; VOGT, G. A. Produtividade de forragem em três genótipos de milheto em diferentes doses de cama de aviário. Revista de Ciências Agroveterinárias, v.11, n.1, p.63-69, 2012.

BARBOSA, J. C.; MALHEIROS, E. B.; BANZATTO, D. A. ESTAT: um sistema de análises estatísticas de ensaios agronômicos. Versão 2.0. Jaboticabal: Unesp, 1992.

BASTOS, E. A.; CARDOSO, M. J.; MELO, F. B.; RIBEIRO V. Q.; ANDRADE JÚNIOR, A. S. Doses e formas de parcelamento de nitrogênio para a produção de milho sob plantio direto. Revista Ciência Agronômica, v.39, n.2, p. 275-280, 2008.

BAYER, C.; CERETTA, C. A.; SCHNEIDER, N. G. Viabilidade da utilização de cama de aviário como fertilizante na cultura do milho. Revista Científica Rural, v.2, n. 1, p. 10-14, 1999.

BONO, J. A. M.; FELINI, F. Z. Produtividade de soja e milho, em sistema de plantio com uso de cama de frango na região de Sidrolândia-MS. Ensaios e Ciência: Ciências Agrárias, Biológicas e da Saúde, v.15, n.5, p.9-18, 2011.

COSTA, A. M.; BORGES, E. N.; SILVA, A. A.; NOLLA, A.; GUIMARÃES, E. C. Potencial de recuperação física de um Latossolo Vermelho, sob pastagem degradada, influenciado pela aplicação de cama de frango. Ciência e Agrotecnologia, v.33, Edição Especial, p.991-1998, 2009. https://doi.org/10.1590/S141370542009000700050
EMBRAPA. Sistema Brasileiro de Classificação de Solos. Rio de Janeiro, 1999.

FALKER AUTOMAÇÃO AGRÍCOLA LTDA. Manual do medidor eletrônico de clorofila ClorofiLOG CFL 1030, Porto Alegre, 2008. 4p.

FELINI, F. Z.; BONO, J. A. M. Produtividade de soja e milho, em sistema de plantio com uso de cama de frango na região de Sidrolândia- MS. Ensaios e Ciência: Ciência Agrárias, Biológicas e da Saúde. v.15, n.5, p.9-18, 2011.

FORNASIERI FILHO, D. A cultura do milho. Jaboticabal: Funep, 1992.

FERREIRA, E.B., CAVALCANTI, P.P., NOGUEIRA, D.A. ExpDes.pt: Pacote Experimental Designs (Portuguese). R package version 1.2.0., 2018. Disponível em: https://CRAN.Rproject.org/package=ExpDes.pt. Acesso em: 11 set. 2018.

GODOY, L. J. G.; BÔAS, R. L. V.; BULL, L. T. Utilização da medida do clorofilômetro no manejo da adubação nitrogenada em plantas de pimentão. Revista Brasileira de Ciência do Solo, v.27, n.6, p.1049-1056, 2003. https://doi.org/10.1590/S010006832003000600009

HURTADO, S. M. C.; SILVA, C. A.; RESENDE, A. V.; CORAZZA, E. J.; SHIRATSUCHI, L. S.; HIGASHIKAWA, F. S. Sensibilidade do clorofilômetro para diagnóstico nutricional de nitrogênio no milho. Ciência e Agrotecnologia, v.34, n.3, p.688-697, 2010. https://doi.org/10.1590/S141370542010000300023

KIEHL, E. J. Novo fertilizantes orgânicos. Piracicaba: Editora Degaspari, 2010.

MEdeIROS, J. C.; AlBUQUERQUE, J. A.; MAFRA, A. L.; ROSA, J. D.; GATIBONI, L. C. Relação cálcio:magnésio do corretivo da acidez do solo na nutrição e no desenvolvimento inicial de plantas de milho em um Cambissolo Húmico Áplico. Semina: Ciências Agrárias, v. 29, n. 04, p.799806, 2008. https://doi.org/10.5433/16790359.2008v29n4p799

MAGGIO, M. A. Acúmulo de massa seca e extração de nutrientes por plantas de milho 
doce híbrido "Tropical". 2006. 55p. Dissertação (Mestrado em Agricultura Tropical e Subtropical) - Instituto Agronômico de Campinas, CampinasSP, 2006.

NAKAGAWA, J. Compostagem: obtenção e uso. In: ENCONTRO SOBRE MATÉRIA ORGÂNICA DO SOLO: PROBLEMAS E SOLUÇÕES, 1992, Botucatu. Anais... Botucatu: FCA-Unesp, 1992. p.159-187.

NASCIMENTO, F. M; BICUDO, S. J; FERNANDES, D. M; RODRIGUES, J. G. L; FERNANDES, J. C. F. Diagnose foliar em plantas de milho em sistema de semeadura direta em função de doses e épocas de aplicação de nitrogênio. Revista Brasileira de Tecnologia Aplicada nas Ciências

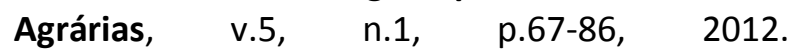
https://doi.org/10.5777/PAeT.V5.N1.04

NOVAKOWISKI, J. H.; SANDINI, I. E. FALBO, M. K. MORAES, A.; NOVAKOWISKI, J. H. Adubação com cama de aviário na produção de milho orgânico em sistema de integração lavoura-pecuária. Semina: Ciências Agrárias, v.34, n.4, p.16631672, 2013. https://doi.org/10.5433/1679$\underline{0359.2013 v 34 n 4 p 1663}$

NOVAES, R. F.; Alvarez V, V. H.; BARROS, N. F.; FONTES, R. L; CANTARUTTI, R. B.; NEVES, J. C. L. Fertilidade do Solo. Viçosa: Sociedade Brasileira de ciência do solo. 2007.

ORRICO JÚNIOR, M. A. P; ORRICO, A. C. A.; DE LUCAS JÚNIOR. Compostagem dos resíduos da produção avícola: cama de frangos e carcaças de aves. Engenharia Agrícola, v.30, n.3, p.538-545, 2010. https://doi.org/10.1590/S010069162010000300017

PAIXÃO, S. L.; CAVALCANTE M.; FERREIRA, P. V.; MADALENA, J. A. S.; PEREIRA, R. G. Divergência genética e avaliação de populações de milho em diferentes ambientes no estado de Alagoas. Revista Caatinga, v.21, n.4, p.191-195, 2008.

PRADO, R. M; ROMUALDO, L. M; ROZANE, D. E. Omissão de macronutrientes no desenvolvimento e no estado nutricional de plantas de sorgo (cv. BRS 3010) cultivadas em solução nutritiva. Científica, Jaboticabal, v.35, n.2, p.122-128, 2007.

PAVINATO, P. S.; CERETTA, C. A; GIOTTO, E.; MOREIRA, I. C. L. Nitrogênio e potássio em milho irrigado: análise técnica e econômica da fertilização. Ciência Rural, v.38, n.2, p.358-364, $2008 . \quad$ https://doi.org/10.1590/S0103$\underline{84782008000200010}$

PEIXOTO FILHO, J. U; FREIRE, M. B. D. S; FREIRE, F. J.; MIRANDA, M. F; PESSOA, L. G; KAMIMURA, K. $M$. Lettuce productivity with doses of poultry, cattle and sheep manure in successive crops. Revista Brasileira de Engenharia Agrícola e Ambiental , v. 17, p. 419-424, 2013. https://doi.org/10.1590/S1415$\underline{43662013000400010}$

$R$ CORE TEAM R: A language and environment for statistical computing. $R$ Foundation for Statistical Computing, Vienna, Austria. URL https://www.R-project.org/.2018. Acesso em 11/09/2018.

RAMBO, L.; SILVA, P. R. F. da; STRIEDER, M. L.; SILVA, A. A. da; SANGOI, L.; VIEIRA, V. M. Índices nutricionais de $\mathrm{N}$ e produtividade de milho em diferentes níveis de manejo e de adubação nitrogenada. Revista Agropecuária Brasileira, v.46, n.4, p.390-397, 2011. https://doi.org/10.1590/S0100$\underline{204 \times 2011000400008}$

RIZZARDI, M. A.; ZANATTA, F. S.; LAMB, T. D.; JOHANN, L. B. Controle de plantas daninhas em milho em função de épocas de aplicação de nitrogênio. Planta Daninha, v.26, n.1, p.113-121, $2008 . \quad$ https://doi.org/10.1590/S0100$\underline{83582008000100012}$

RUTTANAPRASERT, R; JOGLOY, S; VORASOOTN, K. T.; KANWAR, R. S.; HOLBROOK, C. C. Relationship between chlorophyll density and spad chlorophyll meter reading for Jerusalem Artichoke (Helianthus tuberosus L.). Journal of Breeding and Genetics v. 44 p. 149-162, 2012

SANTOS, C. C.; BELLINGIERI, P. A.; FREITAS, J. C. Efeito da aplicação de compostos orgânicos de cama de frango nas propriedades químicas de um Latossolo Vermelho Escuro cultivado com sogro granífero [Sorghum bicolor (L.) Moench]. Científica, v.32, n.2, p.134 -140, 2004. http://dx.doi.org/10.15361/1984-

5529.2004v32n2p134-140

SANTOS, L. B.; CASTAGNARA, D. D.; BULEGON, L. G.; ZOZ, T.; OLIVEIRA, P. S. R.; GONÇALVES JÚNIOR, A. C.; NERES, M. A. Substituição da 
adubação nitrogenada mineral pela cama de frango na sucessão aveia/milho. Bioscience Journal, v.30, n.3, p.272-281, 2014.

SARTAJ, M.; FERNANDES, L.; PATNI, N. K. Performance of forced, passive, and natural aeration methods for composting manure slurries. Transactions of the ASAE, v.40, n.2, p.457-463, 1997. https://doi.org/10.13031/2013.21273

SILVA, C. S.; MURAOKA, T.; GUIMARÃES, G. L.; BUZETTI, S. Acúmulo de nutrientes em plantas de cobertura e no milho cultivado em sucessão sob diferentes doses de nitrogênio em plantio direto. Revista Brasileira de Milho e Sorgo, v.5, n.2, p.202-217, 2006. http://dx.doi.org/10.18512/1980$6477 /$ rbms.v5n02p\%25p

SILVA, J. A.; OLIVEIRA, A. P.; ALVES, G. S.; CAVALCANTE, L. F.; OLIVEIRA, A. N. P.; ARAÚJO, M. A. M. Rendimento do inhame adubado com esterco bovino e biofertilizante no solo e na folha. Revista Brasileira de Engenharia Agrícola e Ambiental, v.16, n.3, p.253-257, 2012. https://doi.org/10.1590/S1415-

$\underline{43662012000300003}$

SORATTO, R. P.; PEREIRA, M.; COSTA, T. A. M.; LAMPERT, V. N. Fontes alternativas e doses de nitrogênio no milho safrinha em sucessão à soja. Revista Ciência Agronômica, v.41, n.4, p.511-518, $2010 . \quad$ https://doi.org/10.1590/S1806$\underline{66902010000400002}$

SORATTO, R. P.; SILVA, A. H.; CARDOSO, S. M.; MEDONÇA, C. G. Doses e fontes alternativas de nitrogênio no milho sob plantio direto em solo arenoso. Ciência e Agrotecnologia, v.35, n.1, p.62-70, 2011. https://doi.org/10.1590/S1413$\underline{70542011000100007}$

VALADÃO, C. A.; MAAS, K. D. B.; WEBER, O. L. S.; VALADÃO JÚNIOR, D. D.; SILVA, T. J. Variação nos atributos do solo em sistemas de manejo com adição de cama de frango. Revista Brasileira de Ciência do Solo, v.35, n.6, p.2073-2082, 2011. https://doi.org/10.1590/S0100-

$\underline{06832011000600022}$

VALDERRAMA, M.; BUZETTI, S.; BENETT, C. G. S.; ANDREOTTI, M.; TEIXEIRA FILHO, M. C. M. Fontes e doses de NPK em milho irrigado sob plantio direto. Pesquisa Agropecuária Tropical, Goiânia, v. $41, \quad$ n. 2, p. 254-263, 2011. https://doi.org/10.5216/pat.v41i2.8390

VARVEL, G. E.; SCHPERS, J. S.; FRANCIS, D. D. Ability for in-season correction of nitrogen deficiency in corn using chlorophyll meters. Soil Science Society of America Journal, v.61, n.4, p.1233-1239, 1997. https://doi.org/10.2136/sssaj1997.03615995006 $\underline{100040032 x}$

Recebido para publicação em 29/08/2017

Revisado em 16/09/2018

Aceito em 13/10/2018 